University of Nebraska - Lincoln

DigitalCommons@University of Nebraska - Lincoln

Faculty Publications, Department of Psychology

Psychology, Department of

December 2003

\title{
Sexual Risk Taking in Adolescence: The Role of Self-Regulation and Attraction to Risk
}

Marcela Raffaelli

University of Nebraska-Lincoln, mraffaelli1@unl.edu

Lisa J. Crockett

University of Nebraska-Lincoln, ecrockett1@unl.edu

Follow this and additional works at: https://digitalcommons.unl.edu/psychfacpub

Part of the Psychiatry and Psychology Commons

Raffaelli, Marcela and Crockett, Lisa J., "Sexual Risk Taking in Adolescence: The Role of Self-Regulation and Attraction to Risk" (2003). Faculty Publications, Department of Psychology. 115.

https://digitalcommons.unl.edu/psychfacpub/115

This Article is brought to you for free and open access by the Psychology, Department of at DigitalCommons@University of Nebraska - Lincoln. It has been accepted for inclusion in Faculty Publications, Department of Psychology by an authorized administrator of DigitalCommons@University of Nebraska - Lincoln. 


\title{
Sexual Risk Taking in Adolescence: The Role of Self-Regulation and Attraction to Risk
}

\author{
Marcela Raffaelli and Lisa J. Crockett \\ University of Nebraska-Lincoln
}

Submitted September 2002; revised June 2003; accepted July 2003.

\begin{abstract}
Precursors of adolescent sexual risk taking were examined in a multiethnic sample consisting of 443 children (51\% girls) of National Longitudinal Survey of Youth participants. Respondents were 12-13 years old in 1994 and 16-17 in 1998. Controlling for demographic and contextual factors, self-regulation - but not risk proneness - was significantly (modestly) associated with overall sexual risk taking 4 years later, Analyses of individual sexual behaviors indicated that self-regulation may affect choices made after becoming sexually active (e.g. number of partners) rather than the initiation of sexual activity. Measures of parent and peer influence had independent effects on sexual risk taking but did not moderate the effects of self-regulation and risk proneness, Findings add to the growing literature on implications of self-regulation for individual development.
\end{abstract}

Marcela Raffaelli, Department of Psychology and Institute for Ethnic Studies, University of Nebraska-Lincoln; Lisa J. Crockett, Department of Psychology, University of Nebraska-Lincoln. Correspondence concerning this article should be addressed to Marcela Raffaelli, Department of Psychology and Institute for Ethnic Studies, 238 Burnett Hall, University of Nebraska: Lincoln, Nebraska 68588-0308. E-mail: mraffaelli1@unl.edu

This research was funded by National Institutes of Health Grant ROI-MH62977 to Marcela Raffaelli and Lisa J. Crockett. Research assistance was provided by Myesha Albert, Jennifer Bowers, Rebecca Colman, Jenenne Geske, Sam Hardy, Kristin Moilanen, Andy Peytchev, Yuh-Ling Shen, and Devan Starks.

One of the major developmental tasks individuals confront during the teen years centers on sexuality. Although sexuality is a normal aspect of adolescence, unprotected sex, particularly with multiple partners, increases the risk of sexually transmitted infections and unplanned pregnancy. There is tremendous variation in the way adolescents handle these potential risks: Some abstain from sex altogether, some have sex with one partner, others use condoms regularly, and some engage in unprotected sex with multiple partners. Because of the detrimental consequences associated with risky sexual behavior, scholars have devoted considerable effort to identifying the predictors of early sexual debut, unprotected intercourse, and sex with multiple partners. Most studies have emphasized contextual factors (e.g., parent and peer characteristics) and biological correlates such as pubertal maturation (see Crockett, Raffaelli, \& Moilanen, 2003, for a review). Less attention has been paid to psychological characteristics that may predispose adolescents to engage in risky sexual behaviors. Yet, studies of other behavioral domains have documented associations between such individual characteristics as "undercontrol" and "sensation-seeking" and adolescents' participation in various kinds of risky behaviors (J. Block, Block, \& Keyes, 1988; Caspi, Henry, McGee, Moffitt, \& Silva, 1995; Zuckerman, 1991). In the present longitudinal analysis we examined the role of two psychological characteristics - self-regulation and risk proneness - in adolescent sexual risk taking.

Over two fifths (46\%) of U.S. high school students who participated in the 2001 Youth Risk Behavior Survey reported engaging in sexual intercourse (Grunbaum et al., 2002) - a considerable decline from prior surveys (e.g., 53\% of high school students who participated in the 1993 survey; Kann et al., 1995). However, many teens still engage in sexual risk taking. About two fifths $(42 \%)$ of students who had sex during the previous 3 months did not use condoms at last intercourse (Grunbaum et al., 2002). The rate of early intercourse is also of concern: One third $(34 \%)$ of 9th-grade students had initiated sexual intercourse. Early intercourse is important because it is associated with lower condom and contraceptive use, thus increasing the risk of pregnancy and exposure to sexually transmitted infections (Manlove \& Terry, 2000; Millstein \& Litt, 1990). Sex with multiple partners also represents a source of risk, and in 2001, $10 \%$ of all 9th graders and $22 \%$ of 12 th graders reported four or more sex partners (Grunbaum et al., 2002). The outcomes of unprotected sexual activity are clear: Young people under the age of 25 account for approximately two thirds of the 12 million cases of sexually transmitted infections other than HIV diagnosed annually in the U.S. (Centers for Disease Control and Prevention, 1999) and nearly half a million 15-19-year-old girls gave birth in 2000 (a rate of 48.7 per 1,000; Moore et al., 2001).

These statistics indicate that potentially risky sexual behaviors are emerging during adolescence. However, it is likely that the proclivities that underlie sexual risk taking are in place before youngsters become sexually involved. Individuals enter adolescence with a set of personality dispositions and behavioral tendencies that influence their subsequent behavior. Thus, it may be possible to identify precursors to adolescent sexual risk taking during earlier developmental periods.

\section{Self-Regulation and Risk Proneness}

Two individual-level characteristics that may be linked to sexual risk taking are self-regulation and risk proneness. There is a fairly substantial body of literature on risk proneness, which is conceptualized as the propensity to be attracted to potentially risky activities. Some scholars propose that this tendency re- 
flects temperamental factors (Zuckerman, 1991) that are presumably present early in life, whereas others consider risky behavior to be the result of attitudinal characteristics like unconventionality (Jessor \& Jessor, 1977) that may emerge later in development. Research supports the notion that sexual behavior is linked to an individual's attraction to, and tolerance of, risk. In a review of the sensation-seeking literature, Zuckerman (1991) concluded that individuals high on sensation-seeking held more permissive sexual attitudes and had more sexual partners and more varied sexual experiences than low sensation-seekers. Similarly, Parley (1991) found that adolescents characterized as arousal seekers began having sexual intercourse an average of 1 year earlier than those characterized as arousal reducers; furthermore, arousal seekers reported greater diversity of partners and more varied sexual behaviors and experiences. Tolerance of deviance (among other variables) longitudinally predicted sexual activity among White and Hispanic (but not African American) adolescents over a 4-year period (Costa, Jessor, Donovan, \& Fortenberry, 1995). Finally, in a cross-sectional analysis, the item "I enjoy taking risks" was associated with lifetime sexual intercourse among both male and female adolescents but not with contraceptive use at last intercourse (Kowaleski-Jones $\&$ Mott, 1998). These findings support the contention that risk proneness may represent a key individual-level predictor of various dimensions of adolescent sexual risk taking.

Self-regulation, conceptualized as the capacity to regulate emotions, attention, and behavior, is less well studied as a predictor of adolescent sexual risk taking. The notion of self-regulation has emerged in several forms in the developmental literature. The Blocks (e.g., J. H. Block \& Block, 1980) highlighted the personality concepts of ego control and ego resilience. Ego control refers to "impulse control and modulation" (p. 41), whereas ego resilience refers to the capacity to vary one's pattern of adaptation in response to environmental demands. The concept of self-regulation encompasses both dimensions, reflecting a capacity for the regulation of behavior as well as the ability to regulate attention and affect in ways that are attuned to contextual demands (Kopp, 1982). Similar constructs in the developmental literature include "self-restraint," "self-control," "delay of gratification," and other characteristics reflecting an internalized capacity to regulate one's emotions, attention, and behavior. ${ }^{1}$ Most scholars agree that the emergence of self-regulation during early childhood is the result of interactions between child characteristics and the environment and that self-regulatory capacities are largely in place by middle childhood (Bronson, 2000; Kopp, 1982), although the capacity to regulate behavior in accordance with long-term goals does not emerge until adolescence (Demetriou, 2000).

Self-regulation (or related constructs) has been linked to various forms of adolescent risk taking in cross-sectional and longitudinal studies. An association between undercontrol during both childhood and adolescence, and adolescent substance use, was reported in one study (J. Block et a1., 1988). In a similar vein, Caspi et al. (1995) reported that lack of control in early childhood predicted externalizing behavior in adolescence. Cross-sectional linkages between delay of gratification and both substance use and school underperformance were reported in a sample of middle and high school students (Wulfert, Block, Santa Ana, Rodriguez, \& Colsman, 2002). Miller and Byrnes (1997) showed that among third, fifth, and seventh graders, personality variables including sensation-seeking, overconfidence, and insensitivity to outcomes were associated with risk taking (assessed with experimental tasks involving skill or chance and with self-ratings of possible responses to hypothetical scenarios).

On the basis of this body of literature, it seems reasonable to hypothesize that children who are poor self-regulators may be at risk for later involvement in risky sexual behavior. Indeed, several scholars (e.g., Miller \& Byrnes, 1997; Mischel, Shoda, \& Rodriguez, 1989) have speculated that self-regulation may be useful in understanding multiple forms of problem behavior, and links between middle childhood self-regulation and adolescent sexual risk taking have been proposed (Feldman \& Weinberger, 1994). To date, however, few studies have empirically examined relations between self-regulation and adolescent sexual risk taking. In a longitudinal study of boys, self-restraint at ages 10-11 (assessed via a combination of teacher ratings and peer nominations) predicted number of sexual partners 4 years later, with boys who were lower in self-restraint subsequently reporting more partners (Feldman \& Brown, 1993). Moreover, childhood parenting factors (e.g., support, rejection) were linked to adolescent sexual behavior both directly and indirectly through childhood self-restraint. The role of self-regulation in girls' sexual behavior has not been examined in longitudinal studies, but cross-sectional research of related constructs suggests a possible link. For example, among adolescent girls seeking clinic services for either contraceptive advice or termination of a pregnancy, impulsiveness significantly predicted membership in the pregnancy group (Rawlings, Boldero, \& Wiseman, 1995). Additionally, in a study of 12 - to 24-year-old females, impulsiveness was associated with early sexual debut, having more than one lifetime sexual partner, not using birth control or condoms at last intercourse, and having had chlamydia (Kahn, Kaplowitz, Goodman, \& Emans, 2002). Impulsivity is one aspect of self-regulation, reflecting the ability (or inability) to regulate one's own actions (e.g., to think before acting, delay gratification, and wait for a desired event; Lengua, 2002). Taken together, these findings suggest that self-regulatory capacities, as well as attraction to risk, may play a pivotal role in adolescent sexual risk taking.

\section{Contextual and Demographic Correlates of Sexual Risk Taking}

Individual characteristics like self-regulation and risk proneness do not operate in isolation; instead, they function within a social context defined by parents and peers. Two contextual variables appear to be especially important for understanding adolescent risk taking: parental involvement in decision making and negative peer pressure. Prior research shows that adolescents who made decisions about clothes, money, and curfew

${ }^{1}$ A related research literature has conceptualized emotionality (defined as the intensity of positive and negative emotional arousal) and regulation (defined as the modulation of emotional responses) as distinct constructs (e.g., Derryberry \& Rothbart, 1988; Eisenberg et al., 1993). Empirical studies indicate that emotionality and regulation covary, with correlations reaching as high as .50-.60 (e.g., Eisenberg et al., 1993; Lengua, West, \& Sandler, 1998). Moreover, factor analytic studies indicate that different measures of emotionality and regulation can form a single factor (e.g., Eisenberg et al., 1995). Thus, this prior research supports our multidimensional conceptualization of self-regulation. 
without parental input reported higher levels of delinquent behavior (Dornbusch et al., 1985). Allowing adolescents to make decisions on their own may be particularly dangerous when the adolescent has poor self-regulatory skills or is attracted to risk, because such adolescents may make poor decisions when given the opportunity to engage in risky behavior. Similarly, negative peer pressure may increase adolescent risk taking. Adolescents who report more pressure to engage in misconduct also report more involvement in substance use and delinquent behavior (Brown, Clasen, \& Eicher, 1986). Furthermore, adolescents who are attracted to risk may be especially susceptible to negative peer pressure. Along these lines, Miller and Byrnes (1997) proposed that individual propensities would interact with contextual factors like parenting practices and opportunities for risk taking provided by peers. In our analysis, we considered the extent to which adolescents were allowed to engage in autonomous decision making (without parental input) and their perceptions of peer pressure to engage in misconduct.

A number of demographic characteristics have been linked to adolescent sexual risk taking. Family structure, maternal education, and mother's age at the birth of her first child are associated with age at first intercourse and contraceptive use (Blum et al., 2000; Cooksey, Rindfuss, \& Guilkey, 1996; Crockett, Bingham, Chopak, \& Vicary, 1996; Day, 1992; Devine, Long, \& Forehand, 1993). Individual characteristics such as age, gender, and race/ ethnicity have also been tied to the likelihood of sexual activity, age at first intercourse, and number of partners (Crockett et al., 2003). For example, among in-school youth, the proportion reporting sexual experience increased from 34\% among 9th graders to $60.5 \%$ among 12th graders (Grunbaum et al., 2002). The same survey showed that overall, less than half of White $(43 \%)$ and Hispanic (48\%) high school students reported sexual intercourse, compared with over half $(61 \%)$ of Blacks. In general, boys started having sexual intercourse earlier than girls: $40.5 \%$ of 9th-grade boys, and $29 \%$ of 9th-grade girls, reported that they had already had sex (Grunbaum et al., 2002). On the basis of these findings, demographic characteristics including age, gender, race/ethnicity, family structure, maternal education, and mother's age at first birth were included in the current analysis.

\section{Overview of the Current Study}

Our goal was to examine how self-regulation and risk proneness assessed during early adolescence (ages 12-13) operate to predict sexual risk taking in later adolescence as teens begin to explore their sexuality. Consistent with the notion that adolescents carry with them a set of proclivities that may decrease or increase their tendency to engage in potentially risky behavior, we hypothesized that young adolescents with good selfregulatory skills would be less likely to engage in sexual risk taking (indexed by having sex, early first intercourse, multiple sex partners, and inconsistent condom use). Teenagers with good self-regulatory skills should be able to focus on risks present in a sexual situation (regulation of attention) and resist acting impulsively (regulation of behavior). They should also be able to use mental strategies that help them avoid getting carried away by their arousal (regulation of emotion). Thus, they should be less likely to engage in unprotected intercourse, particularly with multiple partners. Adolescents with low levels of risk proneness should be less likely to engage in sexual risk taking because they are less attracted to unfamiliar or risky situa- tions. They may avoid such situations entirely (e.g., avoid sexual intercourse altogether) or find ways to reduce risk in such situations (e.g., use condoms). The direct effects of self-regulation and risk proneness were examined in the analyses. In addition, because it seems likely that self-regulation and risk proneness might operate together such that adolescents low in self-regulation and high in risk proneness should be at increased risk of sexual risk taking, the interaction between these two variables was examined.

The major focus in these analyses was on the impact of individual-level characteristics that have not been fully examined in past research. On the basis of developmental theory and past research, contextual factors (parent and peer influence) were also included. In considering the influence of parents and peers, we examined both direct and interactive effects. We expected that negative peer pressure would enhance the effects of self-regulation and risk proneness on sexual risk taking. That is, adolescents with low levels of self-regulation or high levels of risk proneness should be particularly vulnerable to negative peer influences. Similarly, high levels of autonomous decision making should increase sexual risk taking primarily among adolescents who were low in self-regulation or high in risk proneness. To evaluate these predictions, we examined the interactions between these contextual variables and the psychological variables of self-regulation and risk proneness.

\section{Method}

\section{Sample}

The analysis draws on two waves of data from the National Longitudinal Survey of Youth (NLSY; Zagorsky \& White, 1999). The NLSY began in 1979 with a national probability sample of 12,686 14- to 21year-olds (female sample $N=6,283$ ). Blacks, Hispanics, and economically disadvantaged non-Hispanic Whites were oversampled (the economically disadvantaged White sample was later dropped). Participants have been surveyed on an annual basis since 1979; beginning in 1986, children of female participants were added to the study and have been assessed every 2 years thereafter. As part of a larger study, we identified a cohort of children 4-5 years old in 1986 ( $N=855$; in cases in which multiple siblings participated in the study, one sibling was randomly selected for inclusion in the sample) and followed at three later time points: 1990, 1994, and 1998. The current analysis used data collected in 1994 and 1998. Participants were 12-13 years old in 1994 (Time 1) and 16-17 years old in 1998 (Time 2). In 1994, 735 youngsters were present in the sample; 653 of these youth $(88.8 \%)$ were also present in 1998.

In the current article, the sample was limited to the 443 respondents who had complete data on all the analysis variables. ${ }^{2}$ The analytic sample (mean age at Time $1=13.29$ years, $S D=0.58$ ) was evenly divided by gender ( $51 \%$ female) and included multiple ethnic groups (34\% Black, 24\% Hispanic, $42 \%$ non-Hispanic, nonBlack). The non-Hispanic, non-Black group was primarily White. To evaluate the impact of limiting the sample to respondents with complete data, we conducted analyses comparing the 443 youth with complete data to those who were either present in 1994 but missing in 1998 ( $N=82$ ) or who were present at both waves but had missing data on one or more variables $(N=210)$. The included and excluded groups were compared on all of the variables from the current analy-

\footnotetext{
${ }^{2}$ We also excluded cases of suspected child abuse by eliminating respondents who reported having had sex before age $10 ; N=19$ of the 653 adolescents in the longitudinal sample.
} 
sis; the only significant difference was in the ethnic distribution of the two groups, $\chi^{2}(2, N=735)=7.15, p<.05$. The analytic sample included proportionately fewer Black (34\% vs. $44 \%)$ and more White ( $42 \%$ vs. $34 \%$ ) participants than the attrited and/or missing data group; similar proportions of Hispanics were present in each group (24\% vs. $22 \%$ ). The two groups did not differ significantly on any other demographic variable (gender, maternal education, family structure) or on the contextual (autonomous decision making, negative peer pressure) or psychological (self-regulation, risk proneness) variables.

\section{Measures}

The current study focused on the measures listed below (see Table 1 for scale descriptives).

Child demographics. Demographic variables were based on mother report at Time 1. Child demographics included age (in years), gender, and race/ethnicity (coded in the NLSY data set as "Black," "Hispanic," or "non-Black, non-Hispanic"; the latter group was predominantly White). For inclusion in regression analyses, child race/ethnicity was dummy coded into two variables ("Hispanic" and "Black") with the White group as the omitted category.

Mother characteristics. Maternal characteristics included mother's age at the birth of her first child $(M=19.03$ years, $S D=2.35)$, maternal education ( $79 \%$ had a high school diploma or GED, $21 \%$ did not), and family structure. Forty-one percent of households included both biological parents, $34 \%$ were single-parent household, and $24 \%$ included the mother and a partner who was not the child's biological father. Two dummy variables were created for family structure ("single parent" and "mother plus partner"), with the "two biological parents" group as the omitted category.

Self-regulation (Time 1). The self-regulation measure consisted of 13 conceptually identified items from the 28-item Behavior Problems Index (Peterson \& Zill, 1986; Zill, 1990). Mothers reported how well each item described their child's behavior in the last 3 months, using a 3-point scale from 1 (often true) to 3 (not true). Consistent with our conceptualization of self-regulation as a multidimensional construct, we included items reflecting regulation of affect, attention, and behavior. Affect items tapped into both emotional volatility (e.g., "he/she has sudden changes in mood or feeling") and intensity of expressed emotion (e.g., "he/she has a very strong temper and loses it easily"). "He/ she has difficulty concentrating, cannot pay attention for long" was an indicator of attention regulation, and "he/she is restless or overly active, cannot sit still" was an indicator of activity regulation. (See the Appendix for a full list of items included in the self-regulation measure.) To ensure that the measure of self-regulation did not overlap with preexisting externalizing problems, we excluded items indicative of antisocial behavior (e.g., bullying, lying, breaking things deliberately),

Table 1

Scale Descriptives

\begin{tabular}{|c|c|c|c|}
\hline Variable & $M$ & $S D$ & Percentage \\
\hline \multicolumn{4}{|l|}{ Predictor variables (Time 1) } \\
\hline Self-regulation & 2.56 & 0.34 & \\
\hline Risk proneness & 2.36 & 0.66 & \\
\hline Autonomous decision making & 0.34 & 0.23 & \\
\hline Peer pressure & 0.21 & 0.41 & \\
\hline \multicolumn{4}{|l|}{ Sexual behavior (Time 2) } \\
\hline Sexual-risk-taking composite & 1.19 & 1.33 & \\
\hline Ever had intercourse ( $\%$ yes) & & & 51.7 \\
\hline Sex before age 15 (\% yes) & & & 25.1 \\
\hline No. of sex partners last year & 1.83 & 1.12 & \\
\hline $\begin{array}{l}\text { Did not use condom at last intercourse } \\
(\% \text { no })^{\mathrm{a}}\end{array}$ & & & 37.3 \\
\hline
\end{tabular}

Note. $N=443$ unless otherwise indicated. All scales are scored such that a higher value indicates higher levels of the construct.

${ }^{\text {a }}$ Based on the subset of youth who have had sexual intercourse; $n=229$. peer problems (e.g., trouble getting along with others, not being liked), and oppositional behavior (e.g., disobeying, arguing). Similar items to those included in the self-regulation measures have been used in research that examines emotionality and self-regulation (e.g., Eisenberg et al., 1993, 1995; Lengua, 2002), self-restraint (Feldman \& Brown, 1993), and impulsiveness (Eysenck \& Eysenck, 1978).

Confirmatory factor analysis was conducted to examine the factor structure of the self-regulation construct. Results indicated that a onefactor solution provided an adequate fit to the data (goodness-of-fit in$\mathrm{dex}=.90$; confirmatory fit index $=.92$; root-mean-square error of approximation $=.10$ ). These meet the conventions for adequate model fit (Kelloway, 1998), although the chi-square was significant, as is typical with large samples, $\chi^{2}(65, N=688)=518.46, p<.01$. Factor loadings ranged from .36 to .61 (all significant at $p<.01$ ), with 11 of the 13 factor loadings exceeding .50. Composite scores were computed by averaging across the 13 items ( $\alpha=.85$; mothers must have reported on at least 10 items for a score to be computed). Higher scores correspond to higher levels of self-regulation.

Risk proneness (Time 1). Adolescents responded to six self-report items assessing their attraction to, and tendency to engage in, potentially risky behavior (e.g., "I enjoy taking risks"; "Little Known Variables in the NLS," 2000). Responses were made on a 4-point scale ranging from 1 (strongly disagree) to 4 (strongly agree). Items were averaged to create a composite measure $(\alpha=.67$; respondents must have answered at least five items for a score to be computed). Higher scores indicate greater risk proneness.

Autonomous decision making (Time 1). A measure of the extent to which adolescents were allowed to make decisions without parent input was created from seven self-report questions assessing who made decisions for the child (e.g., "Who usually makes the decisions about how to spend your money?"). A grid listed possible responses as "you," "mother," "father," "stepfather," "friend(s)," and "someone else"; respondents could indicate any possible combination of these responses. The number of times the "child only" response was given was summed and a proportion score computed by dividing by the total number of items; possible scores ranged from 0 to 1 . This approach is similar to that used by Dornbusch and colleagues (Dornbusch et al., 1985; Dornbusch, Ritter, Mont-Reynaud, \& Chen, 1990).

Negative peer pressure (Time 1 ). Self-reported peer pressure to engage in misconduct or delinquent activities was assessed with five yesno items (e.g., "Do you ever feel pressure from your friends to skip school?"). Initially a scale score was computed by averaging across the responses $(\alpha=.72)$. Because the distribution was highly skewed (few adolescents reported peer pressure on any given item), a dichotomous variable was created that indicated whether children reported experiencing any negative peer pressure $(0=n o, 1=y e s)$.

Sexual behavior. At Time 2, adolescents completed self-administered measures of sexual experience. Adolescents were asked whether they had ever had intercourse; those who responded "yes" were asked to report their age at first intercourse, number of sex partners in the last 12 months, and condom use at last intercourse. Sexual risk taking is multidimensional, reflecting a number of different behaviors; therefore, we examined a composite variable indexing the overall degree of sexual risk taking, as well as individual sexual behaviors. The measure of cumulative sexual risk was derived by scoring the different sexual behavior variables dichotomously to indicate whether each type of risk was reported and then counting the number of "yes" responses. Scores ranged from 0 (no risk; i.e., never had sex) to 4 (high risk; i.e., sexually active, sexual debut before age 15 , two or more sex partners in last 12 months, no condom use at last intercourse). Because most prior research has focused on individual outcomes rather than overall risk taking, the four individual measures of sexual risk taking were also considered separately: lifetime sexual intercourse $(0=$ never had sex $1=$ 
had sex), early sexual debut ( $0=$ never had sex or initiated sexual intercourse at age 15 or later, 1 = sexual debut before age 15), condom use at last intercourse $(0=$ used condoms, $1=$ did not use condoms $)$, and number of sexual partners in last 12 months (continuous variable).

\section{Analysis Plan}

Preliminary analyses were conducted to examine bivariate associations among the study variables. Primary analyses involved a sequence of multiple regression models predicting the sexual-risk-taking index. variables were entered in five steps: (1) child demographics (age, gender, ethnicity dummy codes); (2) maternal characteristics (education, family structure dummy codes, age at first birth); (3) individual-level variables (self-regulation and risk proneness); (4) contextual variables (autonomous decision making and peer pressure); and (5) interaction terms between self-regulation and risk proneness and between these two variables and each of the contextual variables, The two individual-level variables were entered before the contextual variables because as internal characteristics, they were the primary focus of the study. The contextual variables, which have been more extensively explored in prior research, were included so that interactive effects with internal individual characteristics could be explored. Follow-up analyses were conducted in which the same sequence of models was tested for each separate indicator of sexual risk (i.e., had sex, sex before age 15, number of sexual partners in the past 12 months, and no condom use at last intercourse). Logistic regression was substituted for linear regression in the case of dichotomous outcome variables.

\section{Results}

\section{Preliminary Analyses}

Bivariate correlations among the study variables are shown in Table 2. Fourteen of the 78 correlations were significant at $p$ $<.001$ (equivalent to an overall $p$-level of .05). Significant correlations ranged in magnitude from .16 to .41 (in the small to medium range; Cohen, 1988). Among demographic variables, mother's age at the birth of her first child was significantly associated with child's age in 1994, ethnicity, family structure, and maternal education. Early childbearers had older children and were more likely to be Black and in a one-parent family in 1994, and less likely to have a high school diploma or GED. Be- ing Hispanic was negatively associated with high school completion, and Black participants were more likely to be in oneparent families.

Turning to interrelations between demographic and other study variables, child age was positively associated with sexual risk taking and with autonomous decision making. Earlier maternal age at first birth and being in a one-parent family at Time 1 were each associated with sexual risk taking at Time 2. Selfregulation and risk proneness at Time 1 were not significantly associated with Time 2 sexual risk taking with the correction for multiple correlations, although they were both significant $(p<$ .05 ) before the correction. Adolescent reports of autonomous decision making and negative peer pressure at Time 1 were positively associated with sexual risk taking 4 years later. The two individual-level predictors, self-regulation and risk proneness, were not significantly correlated with each other, suggesting that they tap different psychological domains.

\section{Longitudinal Prediction of Overall Level of Sexual Risk Taking}

Multiple regression analysis was conducted to evaluate the predictive role of self-regulation and risk proneness on sexual risk taking. Models included demographic variables as controls and examined both the main effects of the two personality characteristics and their interactions with contextual variables (peer pressure and autonomous decision making). As discussed in the analysis plan, variables were entered in five steps: child demographics, maternal characteristics, individual-level variables, contextual variables, and interaction terms between self-regulation and risk proneness and between these two variables and each of the contextual variables. None of the interactions was significant so the last step is not presented.

The first four steps each resulted in a significant increase in $R^{2}$ (see Table 3 for coefficients and statistics). At the first step (child demographics), age was significant, with older adolescents engaging in higher levels of sexual risk taking. At the second step, both family structure variables were also significant, such that adolescents living in one-parent families or with mother and a partner at Time 1 reported higher levels of sexual risk

Table 2

Bivariate Correlations Among Study Variables

\begin{tabular}{|c|c|c|c|c|c|c|c|c|c|c|c|c|c|}
\hline Variable & 1 & 2 & 3 & 4 & 5 & 6 & 7 & 8 & 9 & 10 & 11 & 12 & 13 \\
\hline 1. Age & - & & & & & & & & & & & & \\
\hline 2. Gender & -.10 & - & & & & & & & & & & & \\
\hline 3. Hispanic & -.08 & -.02 & - & & & & & & & & & & \\
\hline 4. Black & .08 & .01 & $-.40 *$ & - & & & & & & & & & \\
\hline 5. Mother completed HS/GED & -.03 & -.01 & $-.20 *$ & .02 & - & & & & & & & & \\
\hline 6. Single-parent family & .05 & .05 & -.04 & $.29 *$ & -.05 & - & & & & & & & \\
\hline 7. Mother and partner & .02 & -.01 & .07 & -.07 & -.02 & $-.41 *$ & - & & & & & & \\
\hline 8. Mother's age at first birth & $-.16^{*}$ & -.03 & .00 & $-.23 *$ & $.31 *$ & $-.22 *$ & -.09 & - & & & & & \\
\hline 9. Self-regulation & .04 & .08 & -.01 & .00 & .10 & -.04 & -.06 & .06 & - & & & & \\
\hline 10. Risk proneness & .01 & -.11 & -.04 & -.08 & -.05 & .02 & -.04 & .06 & -.06 & - & & & \\
\hline 11. Autonomous decision making & $.21 *$ & .00 & .01 & -.06 & .01 & .00 & .05 & -.05 & .05 & .13 & - & & \\
\hline 12. Peer pressure & .08 & -.09 & .00 & -.04 & -.08 & .11 & -.06 & -.02 & -.04 & .14 & .02 & - & \\
\hline 13. Sexual-risk-taking composite & $.16^{*}$ & .02 & -.02 & .05 & -.13 & $.15^{*}$ & .09 & $-.24 *$ & -.12 & .11 & $.16^{*}$ & $.16^{*}$ & - \\
\hline
\end{tabular}

Note. Categorical variables were coded such that a higher score indicated being female; Hispanic (vs. Black or White); Black (vs. Hispanic or White); mother completed HS/GED (vs. no diploma); single-parent household (vs. intact or mother and partner); mother and partner (vs. intact or single-parent). $\mathrm{HS}=$ high school.

$* p<.05$, with Bonferroni correction. 
Table 3

Multiple Regressions Predicting Sexual Risk Taking at Ages 16-17 From Self-Regulation and Risk Proneness at Ages 12-13

\begin{tabular}{|c|c|c|c|c|c|c|c|c|c|c|c|c|}
\hline \multirow[b]{2}{*}{ Variable } & \multicolumn{3}{|c|}{ Model 1} & \multicolumn{3}{|c|}{ Model 2} & \multicolumn{3}{|c|}{ Model 3} & \multicolumn{3}{|c|}{ Model 4} \\
\hline & $B$ & $S E B$ & $\beta$ & $B$ & $S E B$ & $\beta$ & $B$ & $S E B$ & $\beta$ & $B$ & $S E B$ & $\beta$ \\
\hline Age & $0.03^{* *}$ & 0.01 & .16 & $0.02 *$ & 0.01 & .13 & $0.02 * *$ & 0.01 & .13 & $0.02 *$ & 0.01 & .10 \\
\hline Gender & 0.11 & 0.12 & .04 & 0.06 & 0.12 & .02 & 0.12 & 0.12 & .04 & 0.13 & 0.12 & .05 \\
\hline Hispanic & 0.03 & 0.16 & .01 & -0.16 & 0.16 & -.05 & -0.11 & 0.16 & -.04 & -0.10 & 0.16 & -.03 \\
\hline Black & 0.12 & 0.14 & .04 & -0.14 & 0.15 & -.05 & -0.10 & 0.15 & -.04 & -0.04 & 0.15 & -.02 \\
\hline Mother completed HS/GED & & & & -0.26 & 0.16 & -.08 & -0.20 & 0.16 & -.06 & -0.19 & 0.16 & -.06 \\
\hline Single-parent family & & & & $0.50 * *$ & 0.15 & .18 & $0.46 * *$ & 0.15 & .17 & $0.41 * *$ & 0.15 & .15 \\
\hline Mother and partner & & & & $0.45 * *$ & 0.16 & .15 & $0.43 * *$ & 0.16 & .14 & $0.41 * *$ & 0.15 & .13 \\
\hline Mother's age at first birth & & & & $-0.09 * *$ & 0.03 & -.15 & $-0.09 * *$ & 0.03 & -.16 & $-0.09 * *$ & 0.03 & -.15 \\
\hline Self-regulation & & & & & & & $-0.36^{*}$ & 0.18 & -.09 & $-0.38 *$ & 0.18 & -.10 \\
\hline Risk-proneness & & & & & & & $0.22 *$ & 0.09 & .11 & 0.16 & 0.09 & .08 \\
\hline \multicolumn{13}{|l|}{ Autonomous decision } \\
\hline making & & & & & & & & & & $.70 * *$ & .27 & .12 \\
\hline Peer pressure & & & & & & & & & & $.42 * *$ & .15 & .13 \\
\hline$R^{2}$ & & .03 & & & .11 & & & .13 & & & .16 & \\
\hline$F$ & & $3.30 *$ & & & $6.45^{* *}$ & & & $6.29 * *$ & & & $6.60 * *$ & \\
\hline$R^{2}$ change & & .03 & & & .08 & & & .02 & & & .03 & \\
\hline$F$ change & & $3.30 *$ & & & $9.36 * *$ & & & $5.13 * *$ & & & $7.27^{* *}$ & \\
\hline
\end{tabular}

Note. $\quad N=443$. $\mathrm{HS}=$ high school.

$* p<.05 . \quad * * p<.01$.

taking than those in two-parent families. Additionally, mother's age at the birth of her first child was significant: younger maternal age at first birth was associated with higher levels of adolescent sexual risk taking. Age, family structure, and mother's age at first birth remained significant at all subsequent steps; gender, race, and maternal education were never significant.

Both individual-level characteristics added on the third step were significant. Self-regulation showed a negative association, and risk proneness a positive association, with sexual risk taking. That is, adolescents with lower levels of self-regulation and higher levels of risk proneness at ages 12-13 reported higher levels of sexual risk taking 4 years later. In the fourth step, both contextual variables were independently associated with sexual risk taking such that negative peer pressure and autonomous decision making positively predicted later sexual risk taking. The addition of these contextual variables resulted in a drop in significance for risk proneness $(p=.08)$, but the effect for selfregulation remained. In the final model, child age, family structure, mother's age at first birth, self-regulation, autonomous decision making, and peer pressure at Time 1 were all significantly associated with Time 2 sexual risk taking, $F(12,430)=6.60$, $p<.01$.

In sum, consistent with predictions, self-regulation in early adolescence was independently associated with the extent of sexual risk taking 4 years later after controlling for demographic and contextual factors. Risk proneness was initially associated with sexual risk taking, but the effect became nonsignificant when contextual factors were included in the model.

\section{Longitudinal Prediction of Different Aspects of Sexual Risk Taking}

The sexual-risk-taking index was composed of four distinct sexual behaviors. It is possible that self-regulation predicts over- all sexual risk taking by influencing some but not all of these variables. Therefore, additional regressions (logistic or linear) were conducted for each of the four sexual behaviors used to create the sexual-risk-taking composite. The entire sample was included in logistic regressions examining the two dichotomous variables of lifetime sexual intercourse (ever had sex) and early sexual debut (sex before age 15). Only youth who had initiated intercourse by Time $2(N=229)$ were included in analyses of number of sex partners in the past year and condom use at last intercourse. The same sequence of models used for the sexual-risktaking composite was tested; however, for simplicity, only the final models are shown in the tables. The interactions were not significant, so they are omitted.

Logistic regressions examining predictors of ever having sex and early sexual debut are summarized in Table 4. In the final model for lifetime intercourse, child age, family structure, and mother's age at first birth were significant: Older youth, those living in families that did not include two biological parents, and those whose mothers were younger when their first child was born had significantly higher odds of being nonvirgins at Time 2, when they were 16-17 years old. Furthermore, teens who reported making their own decisions and experiencing negative peer pressure at ages $12-13$ were significantly more likely to have initiated intercourse 4 years later. Self-regulation was never significant; risk proneness was significant when it was originally entered but dropped out when autonomous decision making and negative peer pressure were entered into the model. The final model was significant, $\chi^{2}(12, N=443)=65.40, p<$ .01 ; however, self-regulation and risk proneness did not contribute to the final model.

In the model predicting early sexual debut (before age 15), mother's age at first birth, autonomous decision making, and peer pressure were significant, $\chi^{2}(12, N=443)=46.36, p<$ .01 . Adolescents whose mothers had given birth at an early age, 
Table 4

Longitudinal Predictors of Sexual Debut and Early Intercourse

\begin{tabular}{|c|c|c|c|c|c|c|}
\hline \multirow[b]{2}{*}{ Predictor } & \multicolumn{3}{|c|}{ Ever had sex } & \multicolumn{3}{|c|}{ Sex before age 15} \\
\hline & $B$ & $S E B$ & $\operatorname{Exp}(B)$ & $B$ & SE B & $\operatorname{Exp}(B)$ \\
\hline \multicolumn{7}{|l|}{ Demographic variables } \\
\hline Age & $0.05^{* *}$ & 0.02 & 1.05 & 0.01 & 0.02 & 1.01 \\
\hline Gender & 0.24 & 0.21 & 1.27 & 0.10 & 0.24 & 1.10 \\
\hline Hispanic & -0.03 & 0.27 & 0.97 & 0.04 & 0.32 & 1.04 \\
\hline Black & 0.00 & 0.26 & 1.00 & 0.16 & 0.29 & 1.18 \\
\hline Mother completed HS/GED & -0.15 & 0.27 & 0.86 & 0.09 & 0.30 & 1.09 \\
\hline Single-parent family & $0.63 *$ & 0.25 & 1.87 & 0.44 & 0.29 & 1.55 \\
\hline Mother and partner & $0.49 \dagger$ & 0.27 & 1.63 & 0.35 & 0.31 & 1.40 \\
\hline Mother's age at first birth & $-0.15 * *$ & 0.05 & 0.86 & $-0.20 * *$ & 0.06 & 0.82 \\
\hline \multicolumn{7}{|l|}{ Psychological characteristics } \\
\hline Self-regulation & -0.39 & 0.31 & 0.68 & -0.52 & 0.34 & 0.60 \\
\hline Risk proneness & 0.27 & 0.16 & 1.30 & 0.30 & 0.18 & 1.35 \\
\hline \multicolumn{7}{|l|}{ Parenting and peer factors } \\
\hline Autonomous decision making & $0.98 *$ & 0.47 & 2.65 & $1.6 * *$ & 0.53 & 4.80 \\
\hline Peer pressure & $0.64 *$ & 0.26 & 1.90 & $0.55^{*}$ & 0.27 & 1.74 \\
\hline
\end{tabular}

Note. $\quad N=443$. HS $=$ high school.

$\dagger p<.08 . * p<.05 . * * p<.01$.

who made decisions without parental input, and who experienced negative peer pressure had significantly higher odds of having sex before age 15 . Self-regulation did not contribute to the model; again, risk proneness was initially significant but became nonsignificant when decision making and negative peer pressure were entered into the model. ${ }^{3}$

Among the subset of youth who had initiated sexual activity, distinct patterns of associations emerged for behaviors that increased risk of potentially negative outcomes (unprotected sex and multiple sex partners). As shown in Table 5, in the logistic regression predicting unprotected sex, condom use at last intercourse was associated with gender, ethnicity, maternal education, and family structure, $\chi^{2}(12, N=229)=33.10, p<.01$. Girls and adolescents living with a single parent or with mother plus partner had increased odds of engaging in unprotected sex; Black (vs. White) adolescents and adolescents whose mothers completed high school had decreased odds of unprotected sex. Self-regulation was significant when it was initially entered (increments in self-regulation were associated with reduced odds of unprotected sex). However, this association dropped to a trend $(p<.07)$ when decision making and peer pressure were added, and remained as a statistical trend in the final model. Risk proneness was never a significant contributor to the model predicting condom use.

Number of sexual partners in the last 12 months was examined with linear regression. The only demographic variable that was significant was gender, with boys reporting more sex partners than girls. Self-regulation was significantly, negatively associated with number of sex partners. Risk proneness, decision making, and peer pressure were not significant predictors. In the final model, only gender and self-regulation contributed uniquely to predicting number of sex partners, $R^{2}=.11, F(12,209)$ $=2.17, p<.05$. Boys and adolescents who were low in selfregulation reported having more sexual partners in the prior 12 months.

To summarize, risk proneness showed an initial effect on whether an adolescent reported having sex and on the probability that first sex occurred before age 15 . However, both of these effects disappeared when autonomous decision making and negative peer pressure were included in the logistic models. In contrast, among youth who had initiated sexual activity, self-regulation was significantly associated with having fewer sex partners in the past year. It was also initially associated with decreased odds of unprotected sex, but this effect was reduced to a trend when autonomous decision making and negative peer pressure were taken into account.

\section{Discussion}

The overarching goal of this article was to explore developmental precursors of adolescent sexual risk taking, with a particular focus on two psychological characteristics - self-regulation and risk proneness. The findings build on and extend the literature in several ways. First, this study involved a large, multiethnic sample that permitted statistical control of relevant demographic variables. Second, the study's longitudinal design allowed us to explore predictive relations over time. Third, we assessed both an overall sexual-risk-taking composite and specific sexual behaviors, permitting a differentiated consideration of sexual risk taking. Finally, the dataset included family and peer factors that have been identified as significant predictors of adolescent sexual risk taking, allowing examination of the unique effects of individual-level variables while controlling for contextual variables.

The results for the sexual risk composite indicate that selfregulation is a significant longitudinal predictor of whether young people will engage in sexual risk taking during their adolescent years. Self-regulation, conceptualized as the ability to regulate emotions, attention, and behavior, was significantly associated with overall sexual risk taking even after autonomous decision-making (the extent to which adolescents made

\footnotetext{
${ }^{3}$ This analysis was replicated in the sample of youth who had initiated sexual activity. The final model was not significant, $\chi^{2}(12, N=229)=$ 15.79, $p>$.10. Similar findings emerged for mother's age at first birth $(B$ $=-0.15, p<.05)$ and autonomous decision making $(B=1.50, p<.05)$ but negative peer pressure was not a significant predictor $(8=0.32, p>.10)$.
} 


\begin{tabular}{|c|c|c|c|c|c|}
\hline \multirow[b]{2}{*}{ Predictor } & \multicolumn{3}{|c|}{ Nonuse of condoms } & \multicolumn{2}{|c|}{ No. of sex partners } \\
\hline & $B$ & $S E B$ & $\operatorname{Exp}(B)$ & $B$ & $\beta$ \\
\hline \multicolumn{6}{|l|}{ Demographic variables } \\
\hline Age & 0.03 & 0.02 & 1.03 & 0.00 & -.02 \\
\hline Gender & $0.76^{*}$ & 0.33 & 2.14 & -0.51 & $-.23 * *$ \\
\hline Hispanic & 0.34 & 0.41 & 1.40 & -0.26 & -.10 \\
\hline Black & $-0.92 *$ & 0.40 & 0.40 & 0.15 & .07 \\
\hline Mother completed HS/GED & $-0.81 *$ & 0.37 & 0.45 & -0.20 & -.08 \\
\hline Single-parent family & $0.98 *$ & 0.42 & 2.67 & -0.13 & -.06 \\
\hline Mother and partner & $0.86 *$ & 0.43 & 2.37 & 0.17 & .07 \\
\hline Mother's age at first birth & 0.03 & 0.08 & 1.03 & 0.00 & .01 \\
\hline \multicolumn{6}{|l|}{ Psychological characteristics } \\
\hline Self-regulation & $-0.84 \dagger$ & 0.47 & 0.43 & -0.45 & $-.14^{*}$ \\
\hline Risk proneness & 0.10 & 0.24 & 1.10 & 0.00 & .02 \\
\hline \multicolumn{6}{|l|}{ Parenting and peer factors } \\
\hline Autonomous decision making & -1.20 & 0.73 & 0.30 & 0.45 & .09 \\
\hline Peer pressure & 0.43 & 0.37 & 1.53 & 0.00 & -.01 \\
\hline
\end{tabular}

Note. $\quad n=229$. HS $=$ high school.

$\dagger p<.08 . \quad * p<.05 . \quad * * p<.01$.

decisions without parental input) and negative peer pressure, as well as multiple demographic factors, were controlled. The fact that these relations emerged across a 4-year period indicates the potential for long term, cumulative effects. Risk proneness, another individual-level variable that has been linked to risk taking in past research, was initially significant in the model for overall sexual risk taking but the relation dropped to a trend once contextual variables were taken into account It should be noted that self-regulation and risk proneness were not significantly correlated and were associated with different specific risk behaviors, suggesting that they reflect distinct psychological processes. Examination of effect sizes provides some perspective on the predictive power of these different variables. Demographic and family characteristics accounted for $3 \%$ and $8 \%$ (respectively) of the variance in the overall regression model predicting sexual risk taking; individual characteristics (self-regulation and risk proneness) accounted for an additional $2 \%$ of variance, and contextual variables accounted for $3 \%$. The magnitude of effects suggests that individual characteristics play a role comparable to demographic and contextual variables in adolescent sexual risk taking.

Analyses of individual sexual behaviors provided a more differentiated picture of the role of psychological variables in sexual risk taking. Self-regulation was not associated with lifetime intercourse or early sexual debut. In contrast, among youngsters who had already engaged in sexual intercourse, there was a significant effect of self-regulation on number of sexual partners in the past year and a trend-level association for condom use. This pattern of findings leads us to speculate that adolescents who are poor self-regulators may be at increased risk not because they are more likely to have sex than adolescents who are good self-regulators but because they develop more risky sexual behavior patterns. In other words, self-regulation may influence choices the adolescent makes after becoming sexually active (e.g., number of sex partners) rather than the initiation of sexual activity per se. Future research is needed to examine the possibility that self-regulation may be particularly important in affecting risky patterns of sexual behavior that unfold following sexual debut.

The findings are largely consistent with past research, although some differences emerged. The finding that lower levels of self-regulation were associated with higher numbers of sexual partners 4 years later replicates prior research that assessed self-regulation in different ways. For example, boys with poor self-restraint reported more sexual partners 4 years later (Feldman \& Brown, 1993), and impulsiveness was concurrently related to young women's number of partners (Kahn et al., 2002). In contrast to the current study, which found no association between self-regulation and ever having sex, both Feldman and Brown (1993) and Kahn et al. (2002) also reported associations between aspects of self-regulation and sexual debut. The difference in findings might reflect the different ages of study samples, variations in study designs (cross-sectional vs. longitudinal), or the inclusion of different control variables in each study. Our finding that self-regulation was associated with specific risk behaviors rather than sexual initiation is consistent with theoretical predictions that self-regulation should be associated with "inappropriate" risk taking (Miller \& Byrnes, 1997). Future research should consider how self-regulation is associated with distinct sexual behaviors that pose different levels of risk to adolescents.

The results for risk proneness were less consistent with expectations and past research. Prior research led us to predict that attraction to risk (sometimes conceptualized as sensation-seeking or arousal-seeking) would be associated with earlier sexual debut and higher levels of sexual involvement (e.g., more sexual partners). In partial support of these expectations, risk proneness was initially associated with overall levels of sexual risk taking; however, the association dropped to nonsignificance when contextual factors reflecting peer and parental influences were entered in the model. Similarly, in analyses of specific sexual behaviors, risk proneness was initially associated with ever having sex and with early sexual debut, as predicted, but these effects dropped out once autonomous decision making 
and negative peer pressure were entered into the models. Risk proneness never predicted number of sexual partners, although such an association was expected on the basis of prior research.

One possible reason for the disparity between the current findings and prior research is how risk proneness was defined and measured. We used a six-item measure, whereas prior research has used single-item measures (e.g., Kowaleski-Jones $\&$ Mott, 1998) or has operationalized the construct in different ways (e.g., Costa et al.'s, 1995, notion of tolerance of deviance reflects attitudes, and Farley's, 1991, arousal-seeking taps into need for novelty and stimulation). Another difference is that the current analysis looked at relations over time, whereas prior studies have often been cross-sectional. Perhaps most important, the current analysis included demographic and contextual factors that may have attenuated the associations between risk proneness and sexual risk taking. The connection between risk proneness and sexual risk taking merits further examination.

Consistent with prior research, contextual factors played a role in adolescent sexual risk taking. Both decision-making autonomy (low parental control) and negative peer pressure independently predicted overall levels of sexual risk taking. Follow-up analyses indicated that the primary impact of autonomous decision making and negative peer pressure occurred for having sex and for early sexual debut; neither variable was associated with condom use or number of partners among sexually active youth. Thus, contextual variables may operate on early forms of sexual risk taking (i.e., initiation) rather than on factors affecting cumulative risk. The results for decision-making autonomy extend the findings of previous research. Dornbusch et al. (1985) reported that adolescents who made decisions about clothes, money, and curfew without parental input showed higher levels of delinquent behavior; the present study indicates that these adolescents are also more likely to initiate sexual activity. Similarly, Brown et al. (1986) demonstrated linkages between negative peer pressure and self-reported misconduct; the current analysis extends this association to risky sexual behavior. Although the predicted direct effects of parenting and peer factors emerged, the hypothesis that these contextual variables would moderate the effects of self-regulation and risk proneness was not supported. Interactions between contextual and psychological variables were never significant, suggesting that the impact of self-regulation and risk proneness is not greater for adolescents who are granted greater decisionmaking autonomy or who experience negative peer pressure. Instead, contextual variables appear to have independent associations with sexual risk taking. This finding merits further investigation in studies with additional measures of parenting and peer influences.

Although not a central focus of the current study, demographic patterns confirm the distinctiveness of different aspects of sexual risk taking. Ever having sex and initiating sex before age 15 were both associated with mother's age at the birth of her first child; ever having sex was also associated with child's age and family structure. In analyses of unprotected sex and number of partners, gender was a significant predictor: Boys had a higher probability of condom use and reported more sex partners in the past year than did girls. Ethnicity, maternal education, and family structure significantly predicted condom use but not number of sex partners. Again, these findings highlight the need to examine specific sexual behaviors separately as well as together to fully understand sexual risk taking.
The limitations of the present study should be kept in mind in interpreting the findings and conceptualizing future research. The study cohort was composed disproportionately of children born to early childbearers. The average age of mothers at the birth of their first child was 19 years; in contrast, the average age of women having their first child in 1981-1982 (when our respondents were born) was around 23 years (Matthews \& Hamilton, 2002). Results could differ in other populations of adolescents; thus, replications are warranted. In addition, as is true in any study based on existing data, the measures are less than optimal. This is particularly true of the selfregulation measure, which was derived from a set of items intended to assess behavior problems rather than normative aspects of self-regulation. Although the selected items fit our conceptual model and confirmatory factor analysis indicated that the global self-regulation measure was adequate, future research should replicate our analyses with a measure that is more specific and differentiated. Furthermore, several items in our measure incorporated both emotionality (e.g., intensity and duration of negative emotions) and self-regulation, dimensions that have been assessed separately in past research (e.g., Derryberry \& Rothbart, 1988; Eisenberg et al., 1993, 1995; Lengua, 2002). Thus, additional work is needed to validate our multidimensional conceptualization of selfregulation. The sexual behavior questions were also not as precise as might be hoped. For example, condom use was reported only for most recent intercourse, and it is not known whether this event was representative of the adolescent's sexual encounters. Similarly, number of sexual partners was reported for the past year, not over the adolescent's life, likely resulting in an underestimate of risk. Future research should replicate the analyses using datasets that include more extensive measures of the study variables. Another limitation imposed by the NLSY dataset is that concurrent or bidirectional relations could not be examined because specific questions were asked only if respondents had reached a certain age (e.g., members of our study cohort were not asked questions about sexual experience at Time 1 because they were under age 14). Finally, most of the measures were based on adolescent selfreport; thus, some of the associations could be .inflated owing to method variance.

Despite these limitations, the present study adds to the literature on developmental antecedents of adolescent behavior by demonstrating linkages between self-regulation and sexual risk taking. Although modest, the associations spanned a 4-year period and persisted even after controlling for demographic and contextual factors. It should also be noted that self-regulation was based on maternal report whereas sexual behavior was based on adolescent self-report; thus, this association is unlikely to reflect method variance. In addition to contributing to the extensive literature on adolescent sexual risk taking, these findings add to the growing literature on self-regulation and its implications for individual functioning and suggest directions for future research.

The findings also have implications for the development of interventions to reduce sexual risk taking among adolescents. These interventions often emphasize social influences (e.g., resistance to peer pressure, enhancing parent-child communication), and the current findings for peer pressure and autonomous decision making confirm the importance of these contextual factors. In addition, the apparent role of self-regulation in subsequent sexual risk taking raises a number of questions, includ- 
ing the intervention potential of a self-regulation model of risk taking. Early adolescence has been recognized as a critical developmental period during which long-term patterns of healthy or potentially harmful behavior are established (Carnegie Council on Adolescent Development, 1989; Crockett \& Crouter, 1995). Our findings suggest that self-regulation may function as an early warning signal, permitting identification of youngsters at risk for later sexual risk taking. Although additional research is needed before firm conclusions can be drawn, ultimately it may be possible to identify children who are predisposed to engage in sexual risk taking well before they initiate any sexual activity.

\section{References}

Block, J., Block, J. H., \& Keyes, S. (1988). Longitudinally foretelling drug usage in adolescence: Early childhood personality and environmental precursors. Child Development, 59, 336-355.

Block, J. H., \& Block, J. (1980). The role of ego-control and ego-resiliency in the organization of behavior. In W. A. Collins (Ed.), Minnesota Symposia on Child Psychology: Vol. 13. Development of cognition, affect and social relations (pp. 39-101). Hillsdale, NJ: Erlbaum.

Blum, R. W., Beuhring, T., Shew, M. L., Bearinger, L. H., Sieving, R. E., \& Resnick, M. D. (2000). The effects of race/ethnicity, income, and family structure on adolescent risk behaviors. American Journal of Public Health, 90, 1879-1884.

Bronson, M. B. (2000). Self-regulation in early childhood: Nature and nurture. New York: Guilford Press.

Brown, B. B., Clasen, D. R., \& Eicher, S. (1986). Perceptions of peer pressure, peer conformity dispositions, and self-reported behavior among adolescents. Developmental Psychology, 22, 521-530.

Carnegie Council on Adolescent Development. (1989). Turning points: Preparing youth for the 21st century. Washington, DC: Author.

Caspi, A., Henry, B., McGee, R. 0., Moffitt, T. E., \& Silva, P. A. (1995). Temperamental origins of child and adolescent behavior problems: From age three to age fifteen. Child Development, 66, 55-68.

Centers for Disease Control and Prevention. (1999). Young people at risk: HIV/AIDS among America's youth. Retrieved December 16, 2002, from Centers for Disease Control and Prevention Web site: http:// www.cdc.gov/hiv/pubs/facts/youth.htm

Cohen, J. (1988). Statistical power analysis for the behavioral sciences (2nd ed.). Hillsdale, NJ: Erlbaum.

Cooksey, E. C., Rindfuss, R. R., \& Guilkey, D. K. (1996). The initiation of adolescent sexual and contraceptive behavior during changing times. Journal of Health and Social Behavior, 37, 59-74.

Costa, F. M., Jessor, R., Donovan, J. E., \& Fortenberry, J. D. (1995). Early initiation of sexual intercourse: The influence of psychosocial unconventionality. Journal of Research on Adolescence, 5, 93-121.

Crockett, L. J., Bingham, C. R., Chopak, J. S., \& Vicary, J. R. (1996). Timing of first sexual intercourse: The role of social control, social learning, and problem behavior. Journal of Youth and Adolescence, 25, $89-111$.

Crockett, L. J., \& Crouter, A. C. (1995). Pathways through adolescence: An overview. In L. J. Crockett \& A. C. Crouter (Eds.), Pathways through adolescence: Individual development in relation to social contexts (pp. 1-12). Mahwah, NJ: Erlbaum.

Crockett, L. J., Raffaelli, M., \& Moilanen, K. (2003). Adolescent sexuality: Behavior and meaning. In G. R. Adams \& M. D. Berzonsky (Eds.), Blackwell handbook of adolescence (pp. 371-392). Oxford, England: Blackwell.

Day, R. D. (1992). The transition to first intercourse among racially and cul- turally diverse youth. Journal of Marriage and the Family, 54, 749762.

Demetriou, A. (2000). Organization and development of self-understanding and self-regulation. In M. Zeidner (Ed.), Handbook of self-regulation (pp. 209-251). San Diego, CA: Academic Press.

Derryberry, D., \& Rothbart, M. K. (1988). Affect, arousal, and attention as components of temperament. Journal of Personality and Social Psychology, 55, 958-966.

Devine, D., Long, P., \& Forehand, R. (1993). A prospective study of adolescent sexual activity: Description, correlates, and predictors. $A d-$ vanced Behavior Research and Therapy, 15, 185-209.

Dornbusch, S. M., Carlsmith, J. M., Bushwall, S. J., Riner, P. L., Liederman, H., Hastorf, A. H., \& Gross, R. T. (1985). Single parents, extended households, and the control of adolescents. Child Development, 56, 326-341.

Dornbusch, S. M., Riner, P. L., Mont-Reynaud, R., \& Chen, Z. (1990). Family decision making and academic performance in a diverse high school population. Journal of Adolescent Research, 5, 143-160.

Eisenberg, N., Fabes, R. A., Bernzweig, J., Karbon, M., Poulin, R., \& Hanish, L. (1993). The relations of emotionality and regulation to preschoolers' social skills and sociometric status. Child Development, 64, 1418-1438.

Eisenberg, N., Fabes, R. A., Murphy, B., Maszk, P., Smith, M., \& Karbon, M. (1995). The role of emotionality and regulation in children's social functioning: A longitudinal study. Child Development, 66, 13601384.

Eysenck, S. B. G., \& Eysenck, H. J. (1978). Impulsiveness and venturesomeness: Their position in a dimensional system of personality description. Psychological Reports, 43, 1247-1255.

Farley, F. (1991). The Type-t personality. In L. P. Lipsin \& L. L. Mitnick (Eds.), Self-regulatory behavior and risk taking: Causes and consequences (pp. 371-382). Norwood, NJ: Ablex Publishing.

Feldman, S. S., \& Brown, N. L. (1993). Family influences on adolescent male sexuality: The mediational role of self-restraint. Social Development, 2, 15-35.

Feldman, S. S., \& Weinberger, D. A. (1994). Self-restraint as a mediator of family influences on boys' delinquent behavior: A longitudinal study. Child Development, 65, 195-211.

Grunbaum, J. A., Kann, L., Kinchen, S. A., Williams, B., Ross, J. G., Lowry, R., \& Kolbe, L. (2002). Youth risk behavior surveillance-United States, 2001. Morbidity and Mortality Weekly Report, 51, No. SS-4.

Jessor, R., \& Jessor, S. (1977). Problem behavior and psychosocial development: A longitudinal study of youth. New York: Academic Press.

Kahn, J. A., Kaplowitz, R. A., Goodman, E., \& Emans, J. (2002). The association between impulsiveness and sexual risk behaviors in adolescent and young adult women. Journal of Adolescent Health, 30, 229-232.

Kann, L., Warren, C. W., Harris, W. A., Collins, J. L., Douglas, K. A., Collins, M. E., et a1. (1995). Youth risk behavior surveillance-United States, 1993. Morbidity and Mortality Weekly Report, 44, No. SS-1.

Kelloway, E. K. (1998). Using LISREL for structural equation modeling. Thousand Oaks, CA: Sage.

Kopp, C. B. (1982). Antecedents of self-regulation: A developmental perspective. Developmental Psychology, 18, 199-214.

Kowaleski-Jones, L., \& Mon, F. L. (1998). Sex, contraception and childbearing among high-risk youth: Do different factors influence males and females? Family Planning Perspectives, 30, 163-169.

Lengua, L. (2002). The contribution of emotionality and self-regulation to the understanding of children's response to multiple risk. Child Development, 73, 144-161. 
Lengua, L., West, S. G., \& Sandler, J. N. (1998). Temperament as a predictor of symptomatology in children: Addressing contamination of measures. Child Development, 69, 164-181.

Little known variables in the NLS: Risk tolerance. (2000). NLS News, No. 00-100, pp. 6-7.

Manlove. J.. \& Terry, E. (2000). Trends in sexual activity and contraceptive use among teens. Child Trends: Research Brief, 2000-03. Retrieved December 16, 2002, from Child Trends Web site: http://www. childtrends.org/PDF/teentrends.pdf

Matthews, T. J., \& Hamilton, B. E. (2002). Mean age of mother, 19792000. National Vital Statistics Reports, 51.

Miller, D. C., \& Byrnes, J. P. (1997). The role of contextual and personal factors in children's risk taking. Developmental Psychology, 33, 814-823.

Millstein, S. G., \& Litt, J. F. (1990). Adolescent health. In S. S. Feldman \& G. R. Elliot (Eds.), At the threshold; The developing adolescent (pp. 431-456). Cambridge, MA: Harvard University Press.

Mischel, W.. Shoda, Y., \& Rodriguez, M. L. (1989, May 26). Delay of gratification in children. Science, 244, 933-938.

Moore, K., Manlove, J., Terry-Humen, E., Williams, S., Papillo; A. R., \& Scarpa, J. (2001). Child trends; Facts at a glance 2001. Retrieved
December 16, 2002, from Child Trends Web site: http://www. childtrends.org/factlink.asp

Peterson, J. L., \& Zill, N. (1986). Marital disruption, parent-child relationships, and behavioral problems in children. Journal of Marriage and the Family, 48, 295-307.

Rawlings, D., Boldero, J., \& Wiseman, F. (1995). The interaction of age with impulsiveness and venturesomeness in the prediction of adolescent sexual behavior. Individual Differences, 19, 117-120.

Wulfert, E., Block, J. A., Santa Ana, E., Rodriguez, M. L., \& Colsman, M. (2002). Impulsive choices and problem behaviors in early and late adolescence. Journal of Personality, 70, 533-552.

Zagorsky, J. L., \& White, L. (1999). NLSY79 user's guide: A guide to the 1979-1998 National Longitudinal Survey of Youth data. Washington, DC: U.S. Department of Labor.

Zill, N. (1990). Behavior Problems Index based on parent report (Publication No. 9103). Washington, DC: Child Trends.

Zuckerman, M. (1991). Sensation seeking: The balance between risk and reward. In L. P. Lipsitt \& L. L. Mitnick (Eds.), Self-regulatory behavior and risk taking: Causes and consequences (pp. 143-152). Norwood, NJ: Ablex Publishing.

Appendix

Items Included in the Self-Regulation Measure

1. He/she has sudden changes in mood or feeling

2. He/she is too fearful or anxious

3. He/she is unhappy, sad, or depressed

4. He/she cries too much

5 . He/she is rather high strung, tense, and nervous

6. He/she is stubborn, sullen, or irritable

7. He/she has a very strong temper and loses it easily

8. He/she has difficulty concentrating, cannot pay attention for long

9. He/she is easily confused, seems to be in a fog

10. He/she is impulsive, or acts without thinking

11. He/she has a lot of difficulty getting his/her mind off certain thoughts (has obsessions)

12. He/she is restless or overly active, cannot sit still

13. He/she worries too much 